\title{
Geração de Empuxo em um Aerofólio em Movimento de Arfagem e Plunge
}

\section{Celso L. T. Covre (IC), William R. Wolf (PQ)}

\section{Resumo}

Através de uma ferramenta computacional foram simulados diversos casos de aerofólios em movimento combinado de arfagem e plunge. Com isso foram obtidos os parâmetros ótimos de propulsão para o movimento de bater de asas (Flapping Flight).

Palavras Chave: Aerodinâmica Não-Estacionária, Flapping Flight, Propulsão.

\section{Introdução}

Recentemente o interesse por dispositivos aéreos não tripulados, popularmente conhecidos como drones, tem reavivado as pesquisas sobre a física do voo de animais e insetos alados. Um tipo especial de drone com amplo potencial militar e em operações de vigilância são os MAVs (Micro Air Vehicles), que possuem uma envergadura de asa da ordem de $15 \mathrm{~cm}$ ou menos (comparável à de um pássaro) e pesam menos de $90 \mathrm{~g}$. Esse tipo de veículo está sujeito a condições de escoamento externo com baixo número de Reynolds e, portanto, a utilização do conceito de asa fixa tornase complexo e ineficiente para tal aplicação. A propulsão através do bater de asas, ou seja, o movimento combinado de arfagem e plunge (movimento vertical do aerofólio) passa então a oferecer eficiências maiores que métodos tradicionais. Assim, objetiva-se obter os parâmetros ótimos para a propulsão através do movimento de bater de asas.

\section{Resultados e Discussão}

Foi criada uma malha computacional de alta resolução em torno do aerofólio e, através de uma ferramenta computacional de simulação numérica, diferentes parâmetros de plunge, arfagem e diferença de fase entre esses dois movimentos foram utilizados para criar situações de propulsão, que podem ser avaliados através da esteira de vórtices de von Kárman, apresentados na figura 1, e da média temporal de velocidades. Como pode ser visto na figura 1 a seguir, os resultados da simulação são próximos dos resultados experimentais ${ }^{1}$.

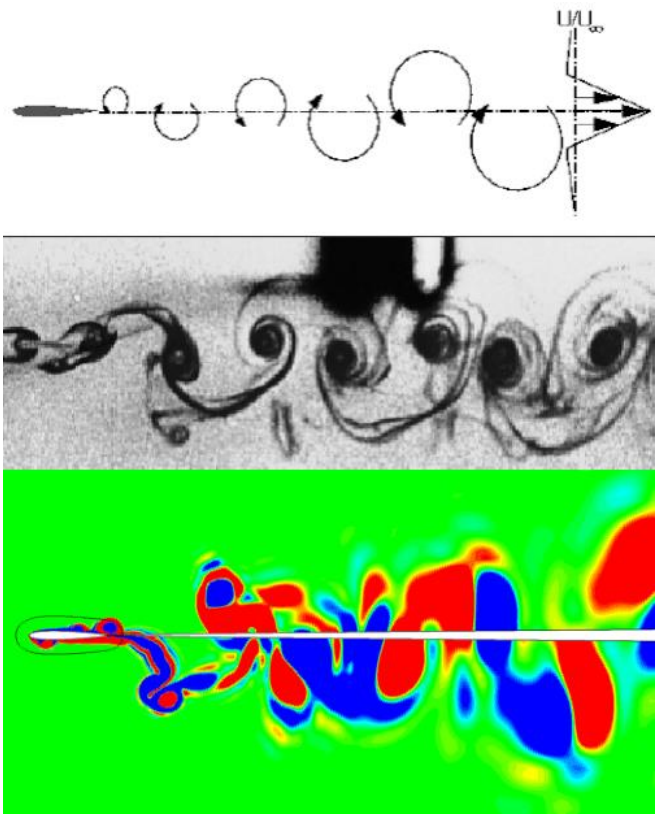

Figura 1. Comparação dos resultados da simulação com os resultados experimentais.

\section{Conclusões}

Os dados encontram-se próximos de dados experimentais verificados na literatura e assim, através das médias temporais, os parâmetros ótimos de propulsão podem ser definidos com elevada acurácia.

\section{Agradecimentos}

Agradeço a minha família, minha noiva, meu orientador e à SAE/UNICAMP por possibilitar o progresso desse trabalho.

\footnotetext{
${ }^{1}$ Jones, K. D.; Dohring C. M. e Platzer, M. F. "Wake Structures Behind Plunging Airfoils: A Comparison of Numerical and Experimental Results", AIAA Meeting Papers on Disc., Jan. 1996, A9610852, AIAA Paper 96-0078.
} 